Supporting Information

\title{
Selective Branching of Plasmonic Photosynthesis into Hydrocarbon Production and Hydrogen Generation
}

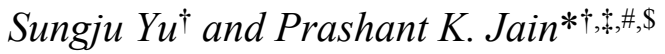

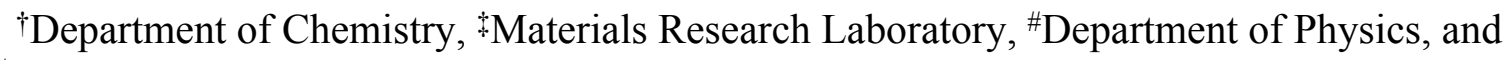
${ }^{\$ B}$ Beckman Institute of Advanced Science and Technology, University of Illinois at UrbanaChampaign, Urbana, Illinois 61801, United States

*Corresponding Author: jain@,illinois.edu 


\section{Experimental Methods}

The preparation and characterization of $\mathrm{Au}$ NPs and supported-NP photocatalysts, photocatalytic reaction studies, and analyses were performed as described previously, ${ }^{1}$ except for one change: the $\mathrm{pH}$ of the reaction medium was controlled and $\mathrm{H}_{2}$ generation was measured at all conditions alongside hydrocarbon production. Photocatalytic reactions were conducted at four different $\mathrm{pH}$ values each at two different concentrations $(5 \mathrm{~mol} \%$ and 25 mol\%) of a solution of the ionic liquid, 1-ethyl-3-methylimidazolium tetrafluoroborate $\left(\mathrm{EMIM}-\mathrm{BF}_{4}\right.$, Aldrich) in deionized (DI) water. The EMIM-BF 4 was dehydrated and degassed

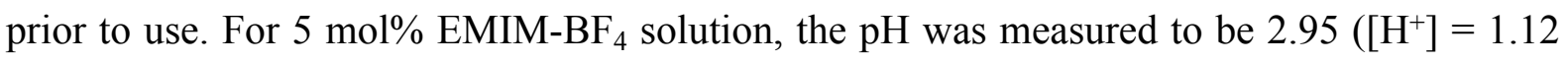
$\mathrm{mM}$ ). To adjust the $\mathrm{pH}$ of the $5 \mathrm{~mol} \% \mathrm{EMIM}-\mathrm{BF}_{4}$ solution, aliquots of $0.1 \mathrm{M}$ aqueous $\mathrm{HNO}_{3}$ were added so as to generate solutions of $\mathrm{pH} 2.53\left(\left[\mathrm{H}^{+}\right]=2.95 \mathrm{mM}\right), \mathrm{pH} 2.33\left(\left[\mathrm{H}^{+}\right]=4.68\right.$ $\mathrm{mM})$, and $\mathrm{pH} 2.16\left(\left[\mathrm{H}^{+}\right]=6.92 \mathrm{mM}\right)$. The total volume of solution was kept fixed. For 25 mol\% EMIM-BF 4 solution, the $\mathrm{pH}$ was measured to be $3.27\left(\left[\mathrm{H}^{+}\right]=0.54 \mathrm{mM}\right)$. In the same way, $25 \mathrm{~mol} \%$ EMIM-BF 4 solutions of $\mathrm{pH} 2.68\left(\left[\mathrm{H}^{+}\right]=2.09 \mathrm{mM}\right), \mathrm{pH} 2.31\left(\left[\mathrm{H}^{+}\right]=4.90\right.$ $\mathrm{mM})$, and $\mathrm{pH} 2.04\left(\left[\mathrm{H}^{+}\right]=9.12 \mathrm{mM}\right)$ were prepared. The $\mathrm{pH}$ values listed are those measured using a $\mathrm{pH}$ meter (Mettler-Toledo AG 8603) for each acid-adjusted EMIM-BF 4 solution under air at room temperature prior to any $\mathrm{CO}_{2}$ bubbling or immersion of the $\mathrm{Au} \mathrm{NP}$ substrate.

A colloid of $\sim 12 \mathrm{~nm}$ diameter polyvinylpyrrolidone (PVP)-coated Au NPs containing $\sim 1.9$ $\times 10^{13} \mathrm{NPs}$ was drop-coated on a $1.5 \mathrm{~cm} \times 1.5 \mathrm{~cm}$ cotton cloth substrate (Texwipe TX 306) that was free of chemical additives. The NP-coated substrate was subject to a washing procedure for cleaning off surface ligands and adsorbates from the NP surfaces, although complete removal cannot be ensured. The Au NP-coated substrate was immersed in $3 \mathrm{~mL}$ of the aqueous EMIM-BF 4 solution contained in an air-tight cell. The resulting reaction mixture was saturated with $\mathrm{CO}_{2}$ by flowing $\mathrm{CO}_{2}$ gas (>99.999\%) through the solution at a rate of 10 $\mathrm{mL} \mathrm{min}^{-1}$ for $20 \mathrm{~min}$ in the dark. Then, the solution was stirred for 30-60 min to facilitate adsorption-desorption equilibrium. The photoreaction was conducted by irradiation of the immersed Au NP-coated substrate by a $532 \mathrm{~nm}$ wavelength beam of an intensity of $1 \mathrm{~W} \mathrm{~cm}^{-2}$ from a continuous-wave (CW) solid-state diode laser (UltraLasers CST-H-532-1500). Gaseous products of the photoreaction collected in the headspace of the reactor were analyzed at periodic intervals using gas chromatography (GC). A GC equipped with a flame ionization detector (FID) was employed for analysis of gaseous hydrocarbon products. A GC equipped with a thermal conductivity detector (TCD) was employed for measuring the 
production of non-hydrocarbons. Data analysis was performed as described in previous work $^{1}$, and turnover numbers (TONs) and turnover frequencies (TOF) were determined for each product. 


\section{Supporting Figures}
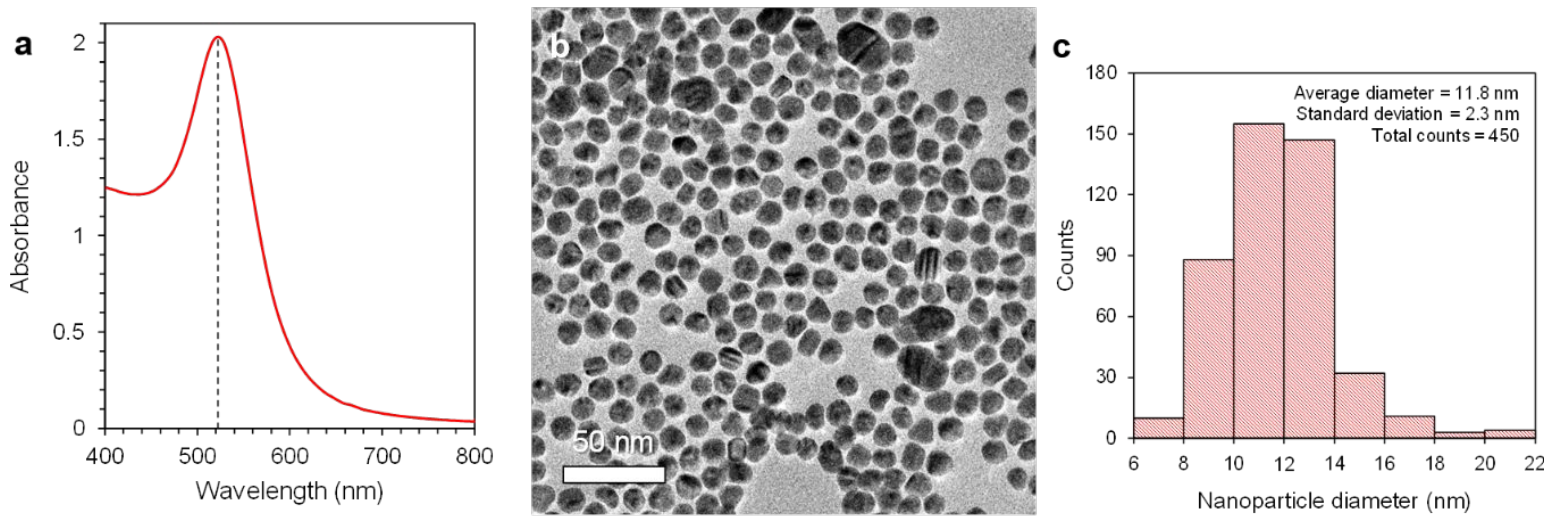

Figure S1. (a) Ultraviolet-visible (UV-vis) extinction spectrum for Au nanoparticle (NP) colloid, which possesses a localized surface plasmon resonance (LSPR) band centered around $520 \mathrm{~nm}$ (dashed line). The Au NP colloid used to prepare the photocatalyst was identical to that used in our past work. ${ }^{2}$ Following up on a suggestion from the reviewers, we provide from this past work ${ }^{2}$ (b) a representative transmission electron microscopy (TEM) image, showing the quasi-spherical shape of the NPs and (c) a histogram of NP diameters estimated from TEM images, showing an average NP diameter of $12 \mathrm{~nm}$. 


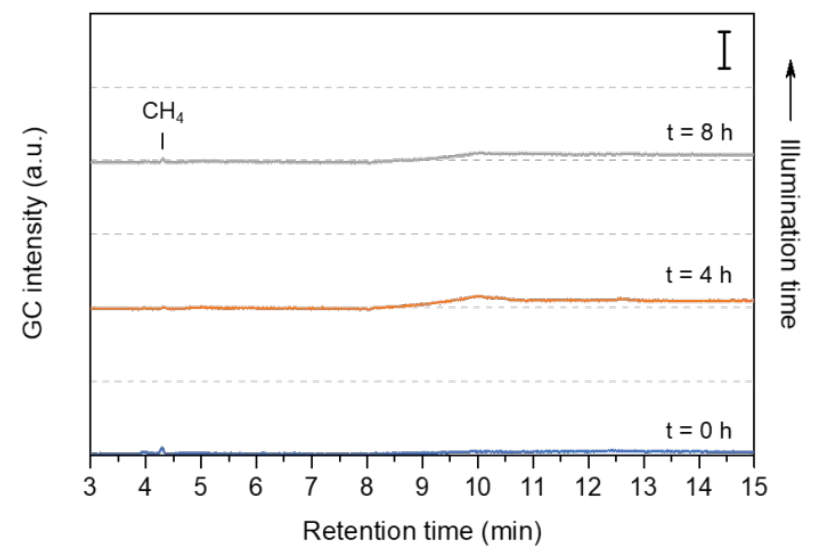

Figure S2. Chromatograms measured by a gas chromatograph equipped with a flame ionization detector (GC-FID) for the gas-phase products of an $8 \mathrm{~h}$ control reaction performed without light irradiation (dark) but at an elevated temperature to account for any photothermal heating. In the photoreactions performed under the irradiation of CW light (532 $\mathrm{nm}, 1 \mathrm{~W} \mathrm{~cm}^{-2}$ ), we measured the steady-state temperature of the bulk reaction mixture to be $\sim 48{ }^{\circ} \mathrm{C}$. For this reason, the dark thermal control reaction was performed at a bulk reaction mixture temperature of $70{ }^{\circ} \mathrm{C}$, which was chosen to be well above the reaction medium temperature in the photoreactions. The dark thermal control reaction was performed without light excitation; but all other conditions matched the photoreaction where the activity was the highest: catalyst film of $\mathrm{Au}$ NPs immersed in $\mathrm{CO}_{2}$-saturated water containing $5 \mathrm{~mol} \%$ EMIM-BF 4 with a $\mathrm{pH}$ of $2.33\left(\left[\mathrm{H}^{+}\right]=4.68 \mathrm{mM}\right)$. Chromatograms are plotted vertically stacked from the bottom to top in order of illumination time: $0 \mathrm{~h}, 4 \mathrm{~h}$, and $8 \mathrm{~h}$. The chromatograms only show a trace of $\mathrm{CH}_{4}$ pre-present (at $\mathrm{t}=0 \mathrm{~h}$ ) as an impurity in the $\mathrm{CO}_{2}$ gas. No generation of hydrocarbon products was measured in this dark thermal reaction. Thus, the observed activity in our photoreactions cannot be attributed to a photothermal effect. Scale bar corresponds to 0.5 a.u.. 

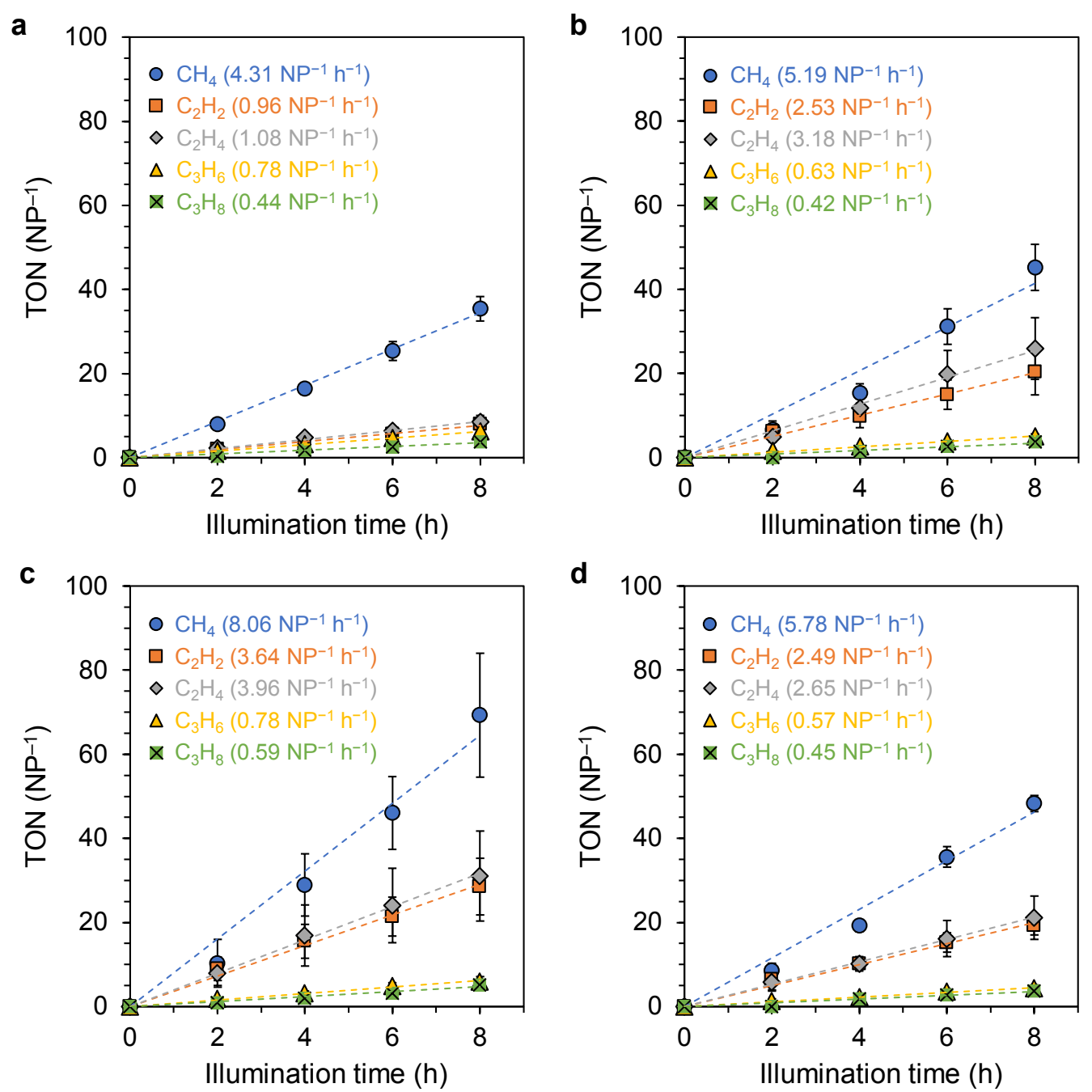

Figure S3. Time course of hydrocarbon turnovers in Au-photocatalyzed $\mathrm{CO}_{2}$ reduction in 5 mol\% EMIM-BF 4 solution of different $\left[\mathrm{H}^{+}\right]$: (a) $1.12 \mathrm{mM}$, (b) $2.95 \mathrm{mM}$, (c) $4.68 \mathrm{mM}$, and (d) $6.92 \mathrm{mM}$. The photoreactions were conducted under the irradiation of a $\mathrm{CW}$ laser of a wavelength of $532 \mathrm{~nm}$ and an intensity of $1 \mathrm{~W} \mathrm{~cm}^{-2}$. Each data point is the average turnover number (TON) from three identical trials, and the error bar is the standard deviation of these measurements. Each dashed line represents a linear fit to the plot, and the slope yields the average turnover frequency (TOF) for each product. These average TOF values are indicated in each plot and plotted as a function of the $\left[\mathrm{H}^{+}\right]$in Figure 1a. For the purpose of comparison of TOFs, all the plots have the same y-axis scale as the plot in panel (c), which presents conditions at which the highest product turnover was observed. 

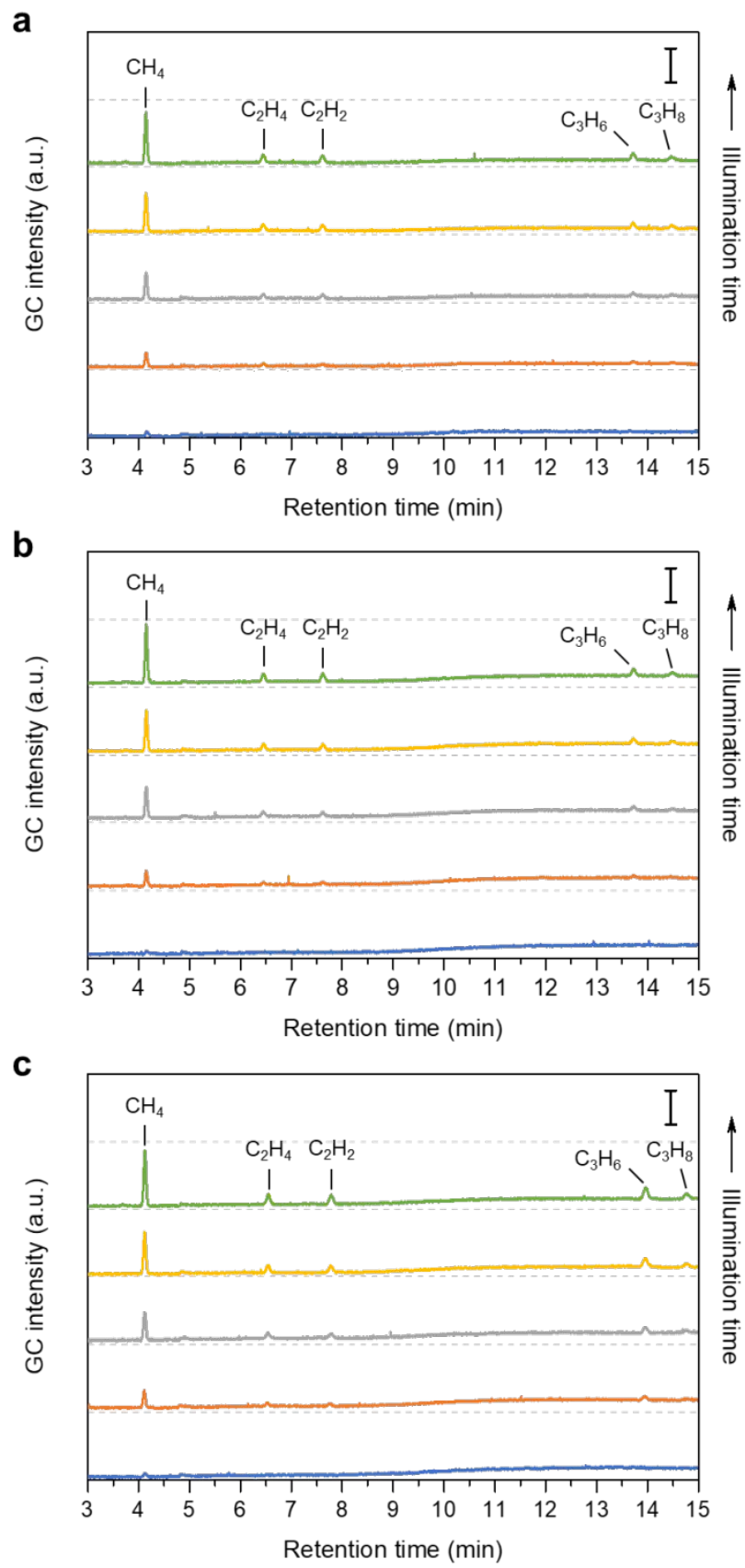

Figure S4. (a-c) Chromatograms from gas chromatography with a flame ionization detector (GC-FID) obtained at $2 \mathrm{~h}$ intervals in an $8 \mathrm{~h}$ long Au-photocatalyzed $\mathrm{CO}_{2}$ reduction reaction

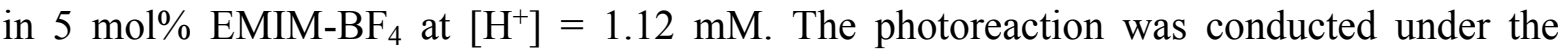
irradiation of a CW laser of a wavelength of $532 \mathrm{~nm}$ and an intensity of $1 \mathrm{~W} \mathrm{~cm}^{-2}$. Three identical trials were performed, results from which are shown in $(\mathrm{a}-\mathrm{c})$. The chromatograms are vertically stacked from the bottom to top in the order of illumination time $(0 \mathrm{~h}, 2 \mathrm{~h}, 4 \mathrm{~h}, 6$ $\mathrm{h}$, and $8 \mathrm{~h}$ ). The chromatograms show an increase in the intensity of GC peaks (labeled) associated with $\mathrm{CH}_{4}, \mathrm{C}_{2} \mathrm{H}_{4}, \mathrm{C}_{2} \mathrm{H}_{2}, \mathrm{C}_{3} \mathrm{H}_{6}$, and $\mathrm{C}_{3} \mathrm{H}_{8}$ with increasing illumination time. The hydrocarbon production was quantified from these chromatograms, the time-profile of which is shown in Figure S3a. Scale bar corresponds to 0.5 a.u.. 

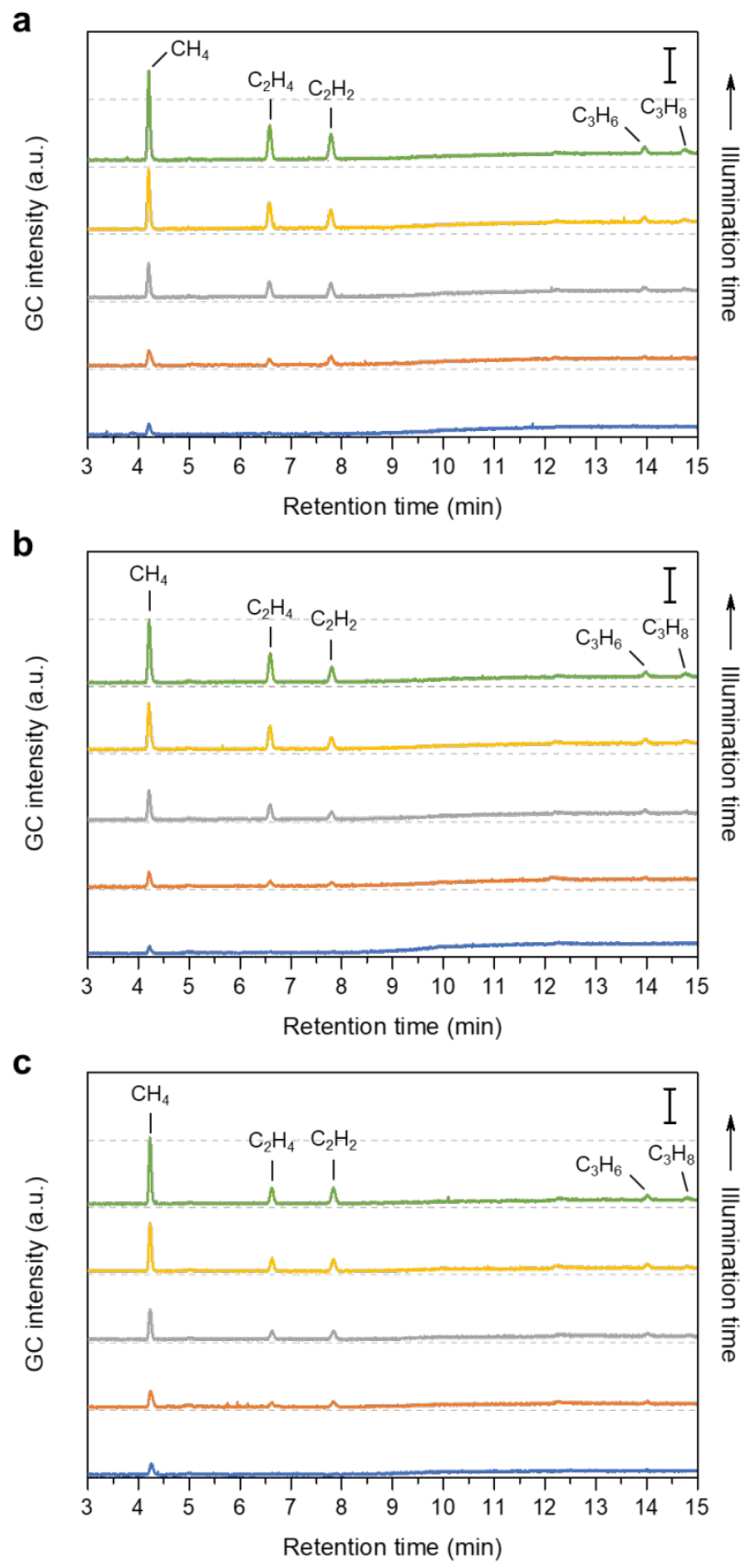

Figure S5. (a-c) GC-FID chromatograms obtained at $2 \mathrm{~h}$ intervals in an $8 \mathrm{~h}$ long Auphotocatalyzed $\mathrm{CO}_{2}$ reduction reaction in $5 \mathrm{~mol} \% \mathrm{EMIM}_{-} \mathrm{BF}_{4}$ at $\left[\mathrm{H}^{+}\right]=2.95 \mathrm{mM}$. The photoreaction was conducted under the irradiation of a CW laser of a wavelength of $532 \mathrm{~nm}$ and an intensity of $1 \mathrm{~W} \mathrm{~cm}^{-2}$. Three identical trials were performed, results from which are shown in $(\mathrm{a}-\mathrm{c})$. The chromatograms are vertically stacked from the bottom to top in the order of illumination time ( $0 \mathrm{~h}, 2 \mathrm{~h}, 4 \mathrm{~h}, 6 \mathrm{~h}$, and $8 \mathrm{~h})$. The chromatograms show an increase in the intensity of $\mathrm{GC}$ peaks (labeled) associated with $\mathrm{CH}_{4}, \mathrm{C}_{2} \mathrm{H}_{4}, \mathrm{C}_{2} \mathrm{H}_{2}, \mathrm{C}_{3} \mathrm{H}_{6}$, and $\mathrm{C}_{3} \mathrm{H}_{8}$ with increasing illumination time. The hydrocarbon production was quantified from these chromatograms, the time-profile of which is shown in Figure S3b. Scale bar corresponds to 0.5 a.u.. 

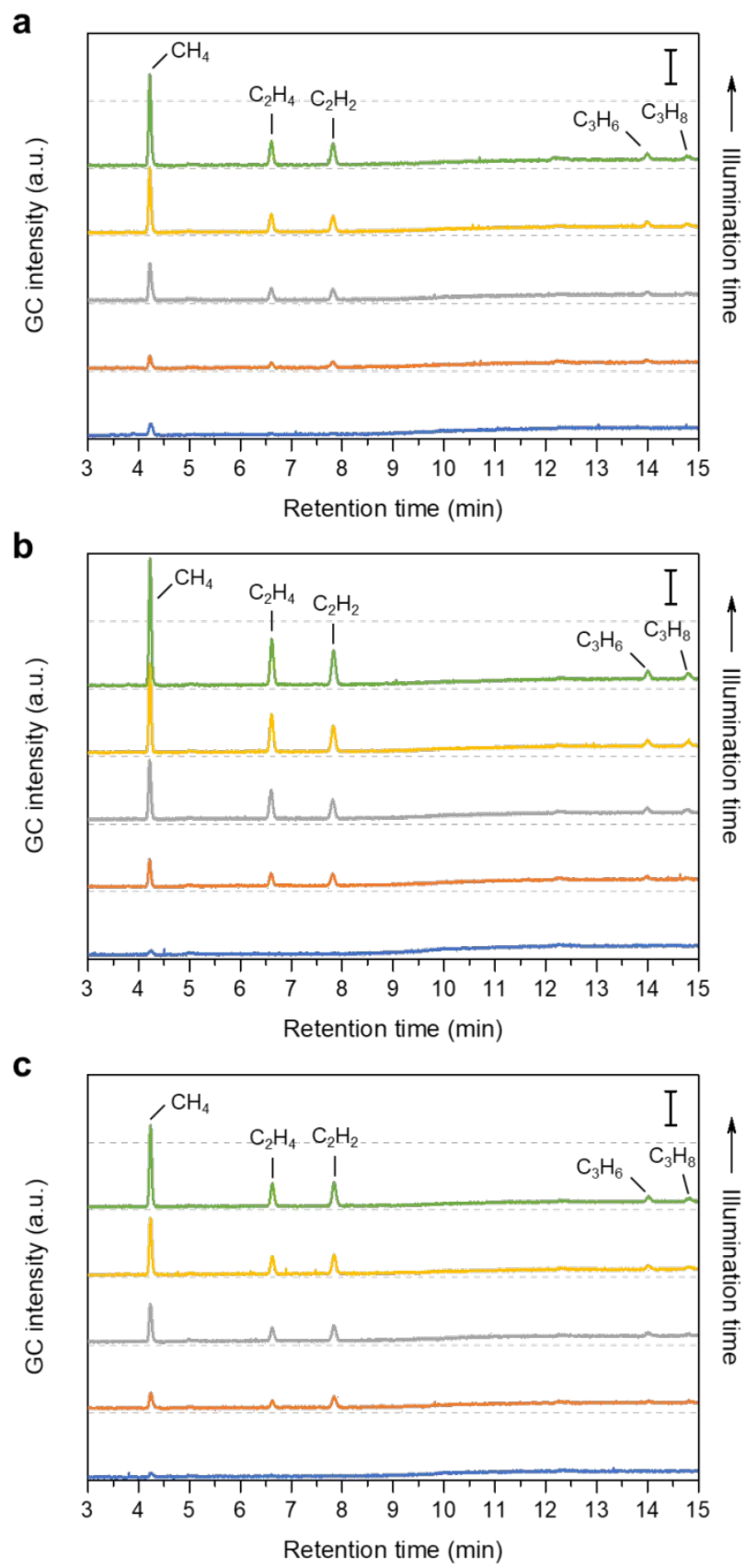

Figure S6. (a-c) GC-FID chromatograms obtained at $2 \mathrm{~h}$ intervals in an $8 \mathrm{~h}$ long Auphotocatalyzed $\mathrm{CO}_{2}$ reduction reaction in $5 \mathrm{~mol} \%$ EMIM- $-\mathrm{BF}_{4}$ at $\left[\mathrm{H}^{+}\right]=4.68 \mathrm{mM}$. The photoreaction was conducted under the irradiation of a CW laser of a wavelength of $532 \mathrm{~nm}$ and an intensity of $1 \mathrm{~W} \mathrm{~cm}^{-2}$. Three identical trials were performed, results from which are shown in $(\mathrm{a}-\mathrm{c})$. The chromatograms are vertically stacked from the bottom to top in the order of illumination time $(0 \mathrm{~h}, 2 \mathrm{~h}, 4 \mathrm{~h}, 6 \mathrm{~h}$, and $8 \mathrm{~h})$. The chromatograms show an increase in the intensity of $\mathrm{GC}$ peaks (labeled) associated with $\mathrm{CH}_{4}, \mathrm{C}_{2} \mathrm{H}_{4}, \mathrm{C}_{2} \mathrm{H}_{2}, \mathrm{C}_{3} \mathrm{H}_{6}$, and $\mathrm{C}_{3} \mathrm{H}_{8}$ with increasing illumination time. The hydrocarbon production was quantified from these chromatograms, the time-profile of which is shown in Figure S3c. Scale bar corresponds to 0.5 a.u.. 

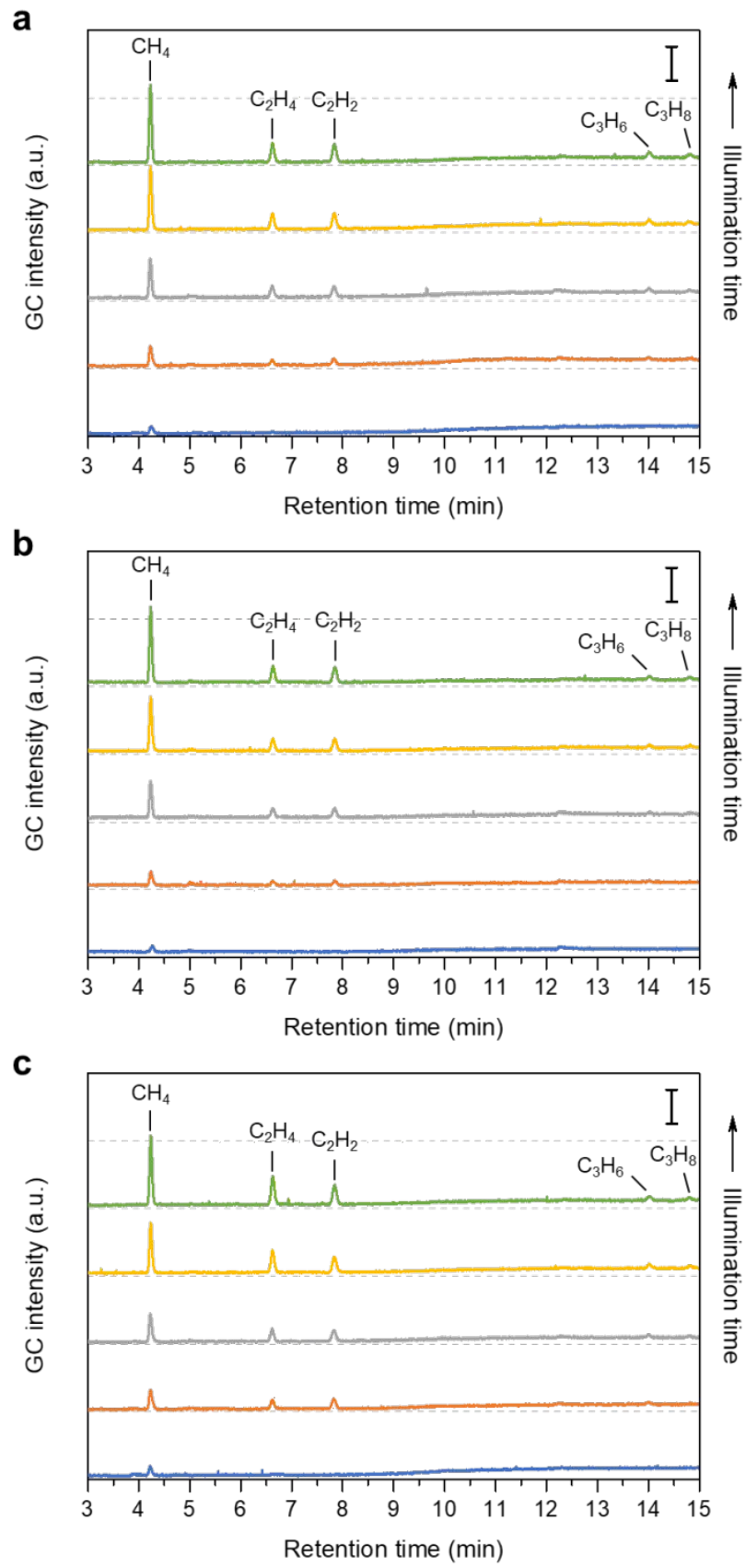

Figure S7. (a-c) GC-FID chromatograms obtained at $2 \mathrm{~h}$ intervals in an $8 \mathrm{~h}$ long Auphotocatalyzed $\mathrm{CO}_{2}$ reduction reaction in $5 \mathrm{~mol} \%$ EMIM- $-\mathrm{BF}_{4}$ at $\left[\mathrm{H}^{+}\right]=6.92 \mathrm{mM}$. The photoreaction was conducted under the irradiation of a CW laser of a wavelength of $532 \mathrm{~nm}$ and an intensity of $1 \mathrm{~W} \mathrm{~cm}^{-2}$. Three identical trials were performed, results from which are shown in $(\mathrm{a}-\mathrm{c})$. The chromatograms are vertically stacked from the bottom to top in the order of illumination time $(0 \mathrm{~h}, 2 \mathrm{~h}, 4 \mathrm{~h}, 6 \mathrm{~h}$, and $8 \mathrm{~h})$. The chromatograms show an increase in the intensity of $\mathrm{GC}$ peaks (labeled) associated with $\mathrm{CH}_{4}, \mathrm{C}_{2} \mathrm{H}_{4}, \mathrm{C}_{2} \mathrm{H}_{2}, \mathrm{C}_{3} \mathrm{H}_{6}$, and $\mathrm{C}_{3} \mathrm{H}_{8}$ with increasing illumination time. The hydrocarbon production was quantified from these chromatograms, the time-profile of which is shown in Figure S3d. Scale bar corresponds to 0.5 a.u.. 

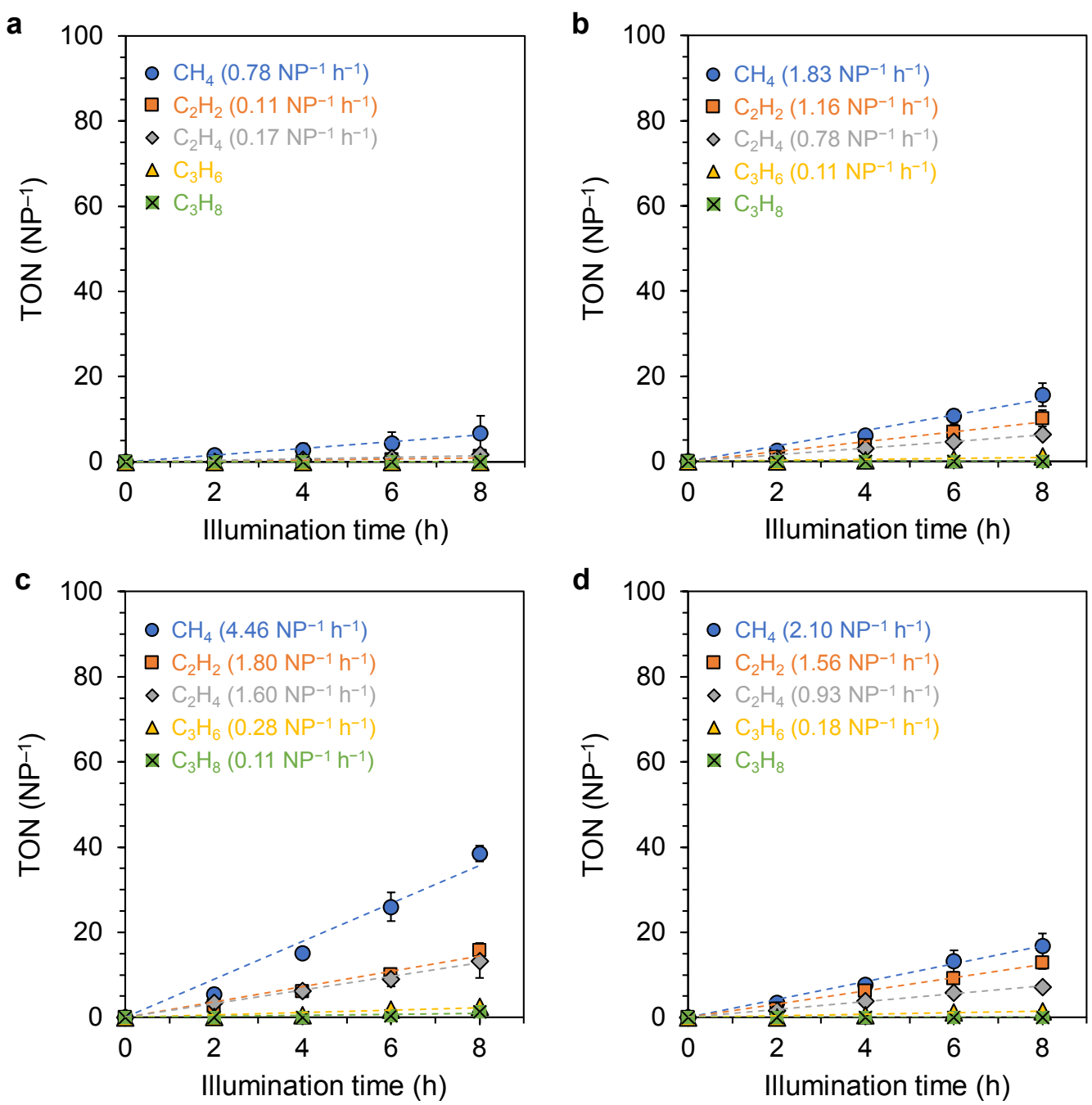

Figure S8. Time course of hydrocarbon turnovers in Au-photocatalyzed $\mathrm{CO}_{2}$ reduction in 25 mol\% EMIM-BF 4 solution at different $\left[\mathrm{H}^{+}\right]$: (a) $0.54 \mathrm{mM}$, (b) $2.09 \mathrm{mM}$, (c) $4.90 \mathrm{mM}$, and (d) $9.12 \mathrm{mM}$. The photoreactions were conducted under the irradiation of a $\mathrm{CW}$ laser of a wavelength of $532 \mathrm{~nm}$ and an intensity of $1 \mathrm{~W} \mathrm{~cm}^{-2}$. Each data point is the average TON from three identical trials, and the error bar is the standard deviation of these measurements. Each dashed line represents a linear fit to the plot, and the slope yields the average TOF of each product. The TOF values are indicated in each plot and plotted as a function of the $\left[\mathrm{H}^{+}\right]$ in Figure 1c. For appropriate comparison of TOFs, all the plots have the same y-axis scale as the plot in Figure S3c, which presents conditions at which the highest product turnover was observed. 

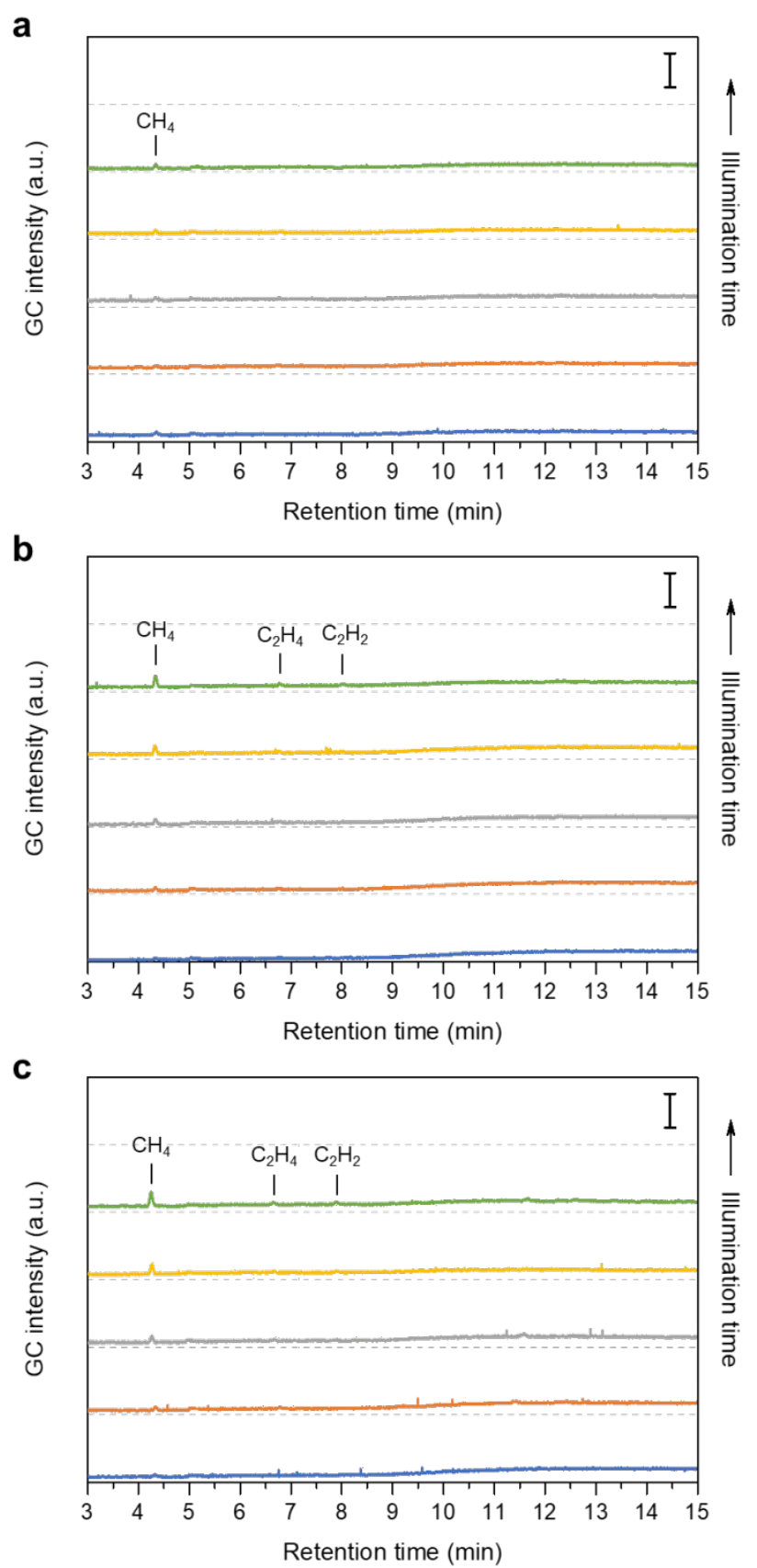

Figure S9. (a-c) GC-FID chromatograms obtained at $2 \mathrm{~h}$ intervals in an $8 \mathrm{~h}$ long Auphotocatalyzed $\mathrm{CO}_{2}$ reduction reaction in $25 \mathrm{~mol} \%$ EMIM- $\mathrm{BF}_{4}$ at $\left[\mathrm{H}^{+}\right]=0.54 \mathrm{mM}$. The photoreaction was conducted under the irradiation of a CW laser of a wavelength of $532 \mathrm{~nm}$ and an intensity of $1 \mathrm{~W} \mathrm{~cm}^{-2}$. Three identical trials were performed, results from which are shown in $(\mathrm{a}-\mathrm{c})$. The chromatograms are vertically stacked from the bottom to top in the order of illumination time ( $0 \mathrm{~h}, 2 \mathrm{~h}, 4 \mathrm{~h}, 6 \mathrm{~h}$, and $8 \mathrm{~h})$. The chromatograms show a small increase in the intensity of GC peak (labeled) associated with $\mathrm{CH}_{4}$ and a minor increase in those of $\mathrm{C}_{2} \mathrm{H}_{4}$ and $\mathrm{C}_{2} \mathrm{H}_{2}$ with increasing illumination time. The hydrocarbon production was quantified from these chromatograms, the time-profile of which is shown in Figure S8a. Scale bar corresponds to 0.5 a.u.. 

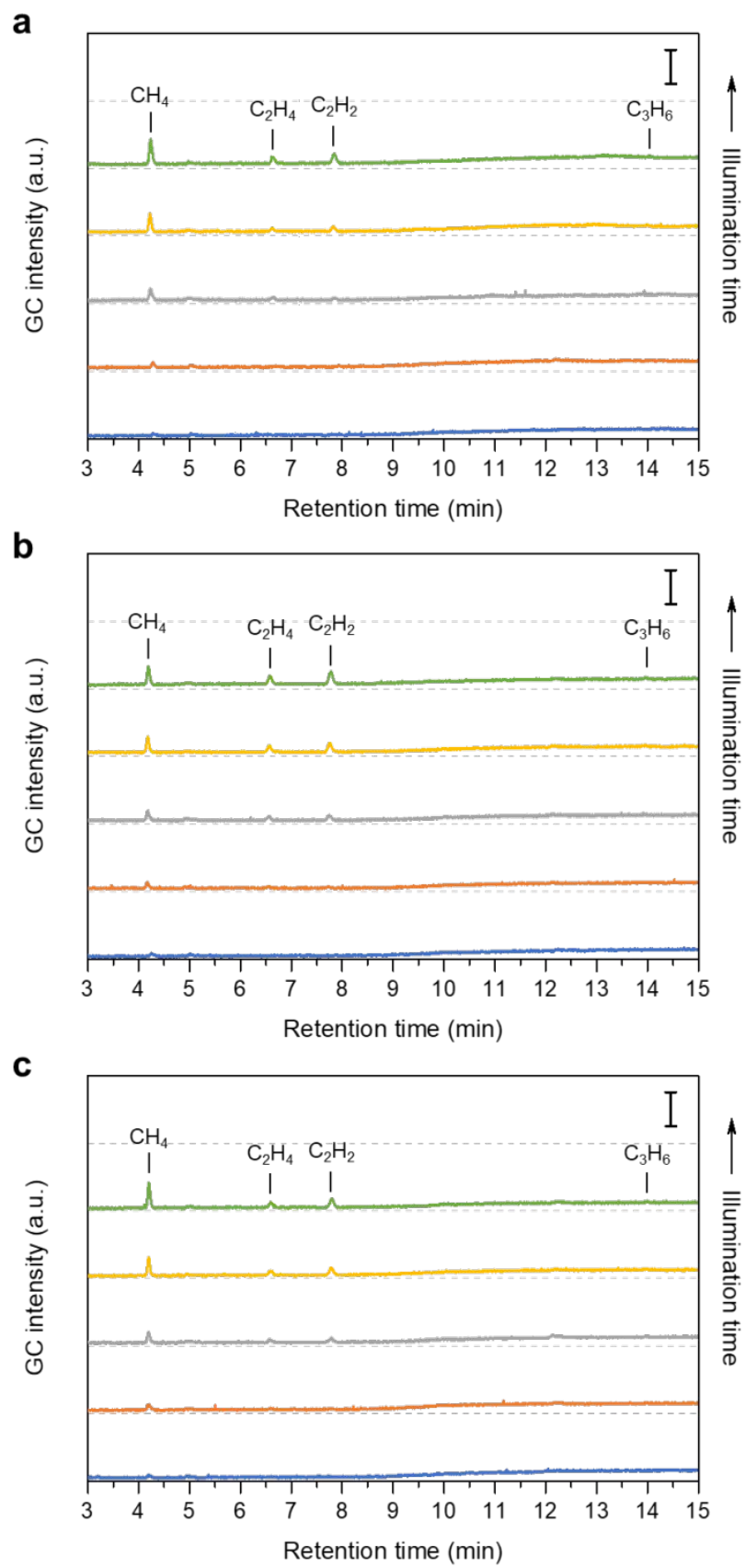

Figure S10. (a-c) GC-FID chromatograms obtained at $2 \mathrm{~h}$ intervals in an $8 \mathrm{~h}$ long Auphotocatalyzed $\mathrm{CO}_{2}$ reduction reaction in $25 \mathrm{~mol} \% \mathrm{EMIM}_{-} \mathrm{BF}_{4}$ at $\left[\mathrm{H}^{+}\right]=2.09 \mathrm{mM}$. The photoreaction was conducted under the irradiation of a CW laser of a wavelength of $532 \mathrm{~nm}$ and an intensity of $1 \mathrm{~W} \mathrm{~cm}^{-2}$. Three identical trials were performed, results from which are shown in $(\mathrm{a}-\mathrm{c})$. The chromatograms are vertically stacked from the bottom to top in the order of illumination time $(0 \mathrm{~h}, 2 \mathrm{~h}, 4 \mathrm{~h}, 6 \mathrm{~h}$, and $8 \mathrm{~h})$. The chromatograms show an increase in the intensity of GC peaks (labeled) associated with $\mathrm{CH}_{4}, \mathrm{C}_{2} \mathrm{H}_{4}$, and $\mathrm{C}_{2} \mathrm{H}_{2}$, and a minor increase in that of $\mathrm{C}_{3} \mathrm{H}_{6}$ with increasing illumination time. The hydrocarbon production was quantified from these chromatograms, the time-profile of which is shown in Figure S8b. Scale bar corresponds to 0.5 a.u.. 

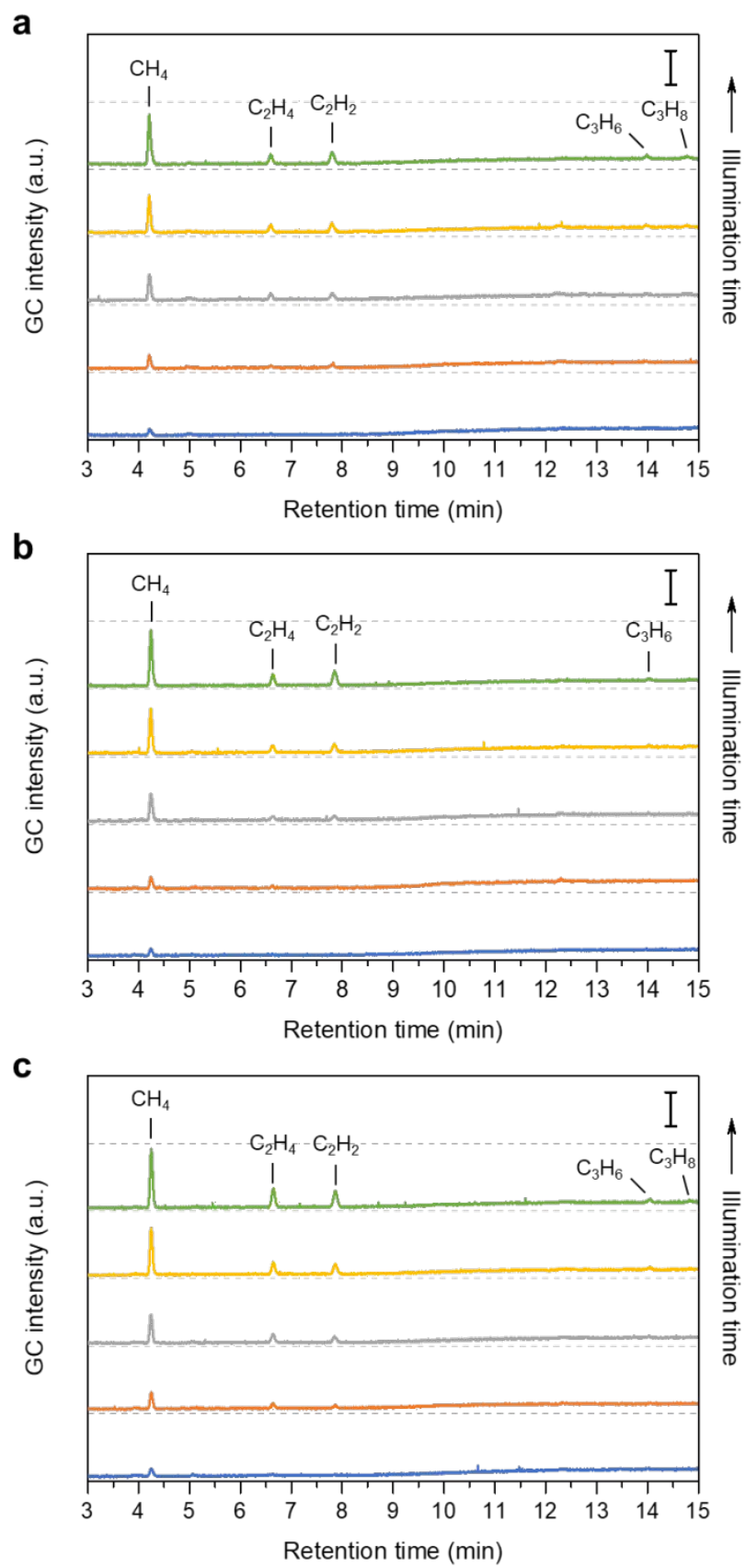

Figure S11. (a-c) GC-FID chromatograms obtained at $2 \mathrm{~h}$ intervals in an $8 \mathrm{~h}$ long Auphotocatalyzed $\mathrm{CO}_{2}$ reduction reaction in $25 \mathrm{~mol} \% \mathrm{EMIM}_{-} \mathrm{BF}_{4}$ at $\left[\mathrm{H}^{+}\right]=4.90 \mathrm{mM}$. The photoreaction was conducted under the irradiation of a CW laser of a wavelength of $532 \mathrm{~nm}$ and an intensity of $1 \mathrm{~W} \mathrm{~cm}^{-2}$. Three identical trials were performed, results from which are shown in $(\mathrm{a}-\mathrm{c})$. The chromatograms are vertically stacked from the bottom to top in the order of illumination time $(0 \mathrm{~h}, 2 \mathrm{~h}, 4 \mathrm{~h}, 6 \mathrm{~h}$, and $8 \mathrm{~h})$. The chromatograms show an increase in the intensity of GC peaks (labeled) associated with $\mathrm{CH}_{4}, \mathrm{C}_{2} \mathrm{H}_{4}$, and $\mathrm{C}_{2} \mathrm{H}_{2}$ and a minor increase in those of $\mathrm{C}_{3} \mathrm{H}_{6}$ and $\mathrm{C}_{3} \mathrm{H}_{8}$ with increasing illumination time. The hydrocarbon production was quantified from these chromatograms, the time-profile of which is shown in Figure S8c. Scale bar corresponds to 0.5 a.u.. 

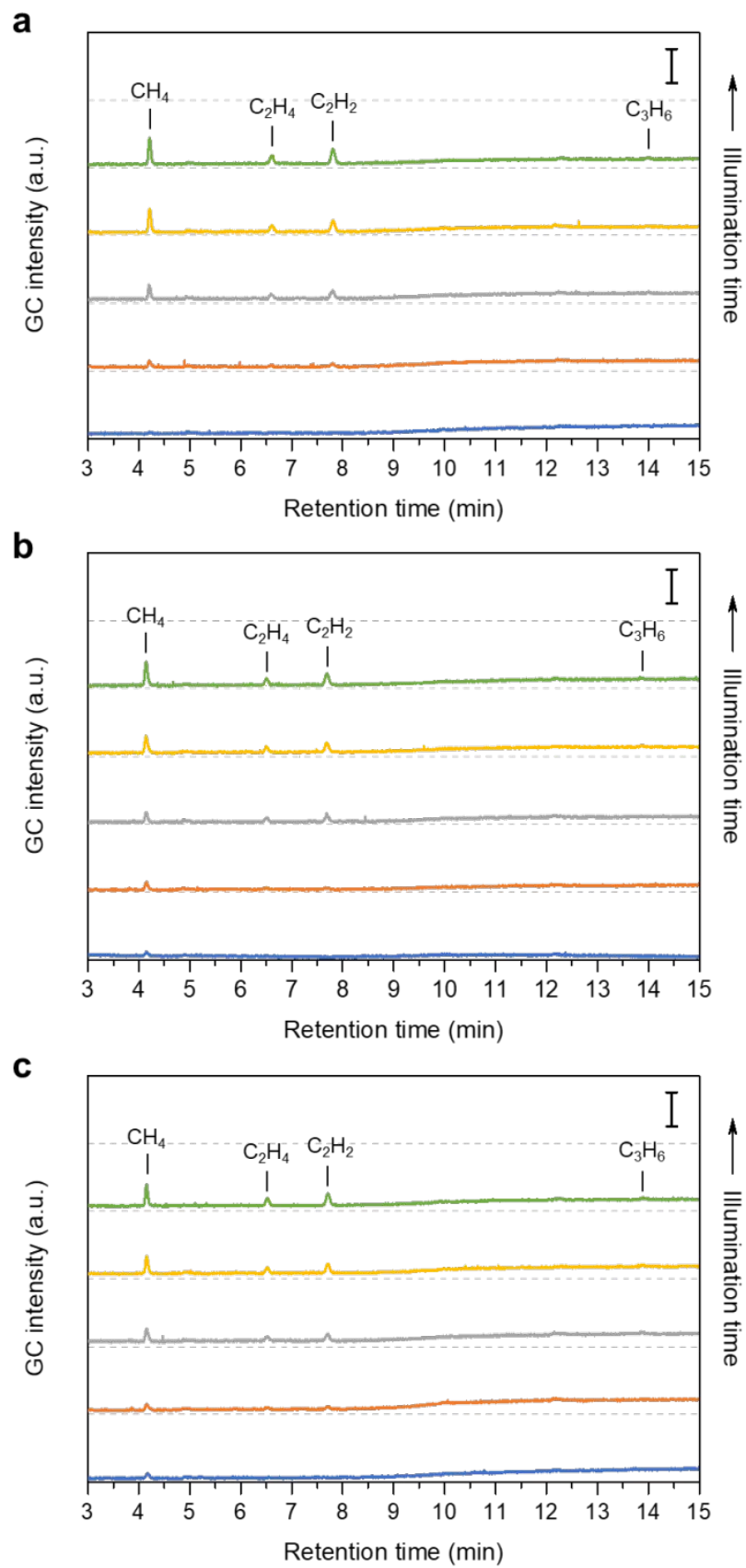

Figure S12. (a-c) GC-FID chromatograms obtained at $2 \mathrm{~h}$ intervals in an $8 \mathrm{~h}$ long Auphotocatalyzed $\mathrm{CO}_{2}$ reduction reaction in $25 \mathrm{~mol} \% \mathrm{EMIM}_{-} \mathrm{BF}_{4}$ at $\left[\mathrm{H}^{+}\right]=9.12 \mathrm{mM}$. The photoreaction was conducted under the irradiation of a CW laser of a wavelength of $532 \mathrm{~nm}$ and an intensity of $1 \mathrm{~W} \mathrm{~cm}^{-2}$. Three identical trials were performed, results from which are shown in $(\mathrm{a}-\mathrm{c})$. The chromatograms are vertically stacked from the bottom to top in the order of illumination time ( $0 \mathrm{~h}, 2 \mathrm{~h}, 4 \mathrm{~h}, 6 \mathrm{~h}$, and $8 \mathrm{~h})$. The chromatograms show an increase in the intensity of $\mathrm{GC}$ peaks (labeled) associated with $\mathrm{CH}_{4}, \mathrm{C}_{2} \mathrm{H}_{4}$, and $\mathrm{C}_{2} \mathrm{H}_{2}$ and a minor increase in that of $\mathrm{C}_{3} \mathrm{H}_{6}$ with increasing illumination time. The hydrocarbon production was quantified from these chromatograms, the time-profile of which is shown in Figure S8d. Scale bar corresponds to 0.5 a.u.. 

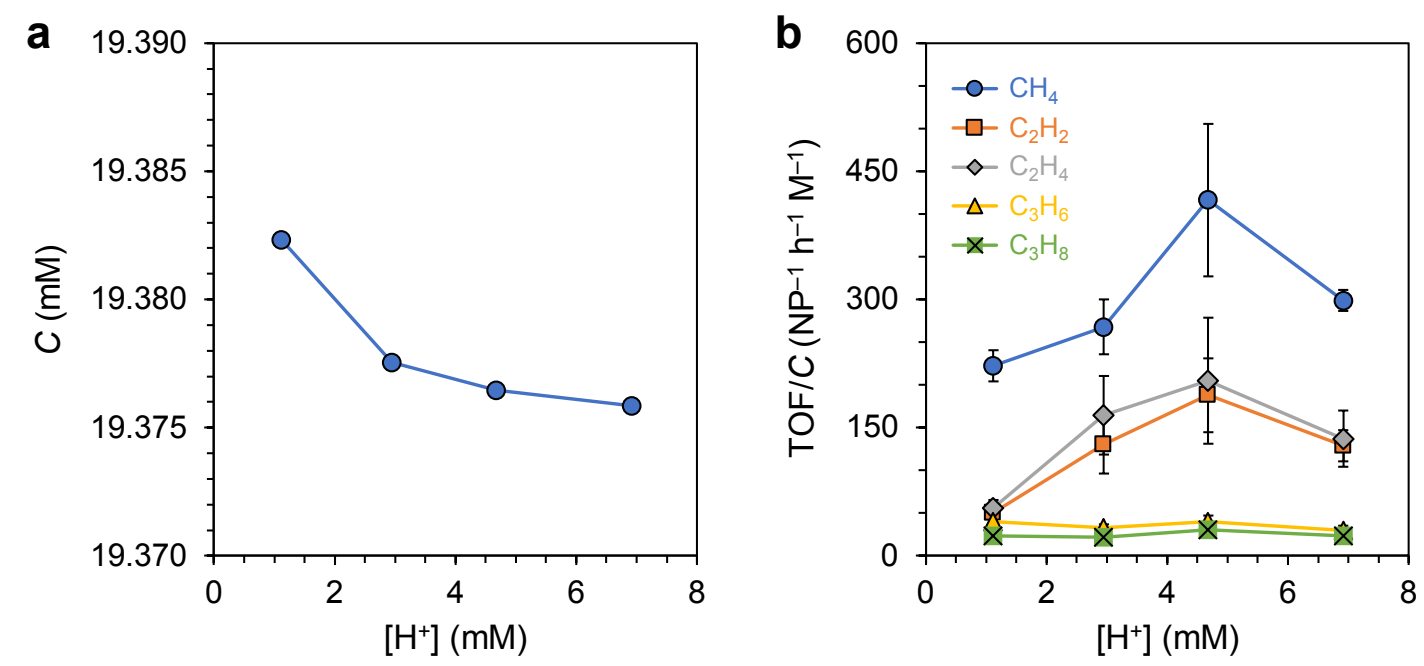

Figure S13. (a) Estimated total concentration, $C$, of dissolved carbonates (in the form of $\mathrm{CO}_{2}$, carbonate, and bicarbonate) in an aqueous solution as a function of $\left[\mathrm{H}^{+}\right]$. The total carbonate concentration does not change much in the $\left[\mathrm{H}^{+}\right]$-range of interest here. For this estimation, we used $C=\left[\mathrm{CO}_{2}\right]_{\mathrm{eq}}\left(\left[\mathrm{H}^{+}\right]^{2}+K_{1}\left[\mathrm{H}^{+}\right]+K_{1} K_{2}\right) /\left[\mathrm{H}^{+}\right]^{2}$ where $K_{\mathrm{a} n}(n=1,2)$ is the $n$-th acid dissociation constant for carbonic acid $\left(\mathrm{H}_{2} \mathrm{CO}_{3}\right)$ at equilibrium and $\left[\mathrm{CO}_{2}\right]_{\mathrm{eq}}$ is the equilibrium concentration of dissolved $\mathrm{CO}_{2}$ in water at $48{ }^{\circ} \mathrm{C}$, which corresponds to the steady-state temperature of the bulk reaction mixture measured in a photoreaction under $\mathrm{CW}$ laser irradiation $\left(532 \mathrm{~nm}, 1 \mathrm{~W} \mathrm{~cm}^{-2}\right)$. The values of the acid dissociation constants were obtained from the known $\mathrm{p} K_{\mathrm{a}}$ s for the diprotic $\mathrm{H}_{2} \mathrm{CO}_{3}: \mathrm{p} K_{\mathrm{a} 1}=6.35$ and $\mathrm{p} K_{\mathrm{a} 2}=10.33$. The $\left[\mathrm{CO}_{2}\right]_{\mathrm{eq}}$ was determined using Henry's law using the Henry's constant for $\mathrm{CO}_{2}$ in water $\left(0.035 \mathrm{~mol} \mathrm{~kg}^{-1}\right.$ bar $^{-1}$, as per the National Institute of Standards and Technology (NIST) Chemistry WebBook) and a $\mathrm{CO}_{2}$ pressure of 1 bar. (b) TOFs of hydrocarbon products generated in the $\mathrm{CO}_{2} \mathrm{RR}$ in $5 \mathrm{~mol} \% \mathrm{EMIM}-\mathrm{BF}_{4}$ (from Figure 1a) normalized by the total carbonate concentration, $C$, and plotted as a function of the $\left[\mathrm{H}^{+}\right]$. Each data point is the average of results from three identical trials and the error bar represents the standard deviation of these measurements. 

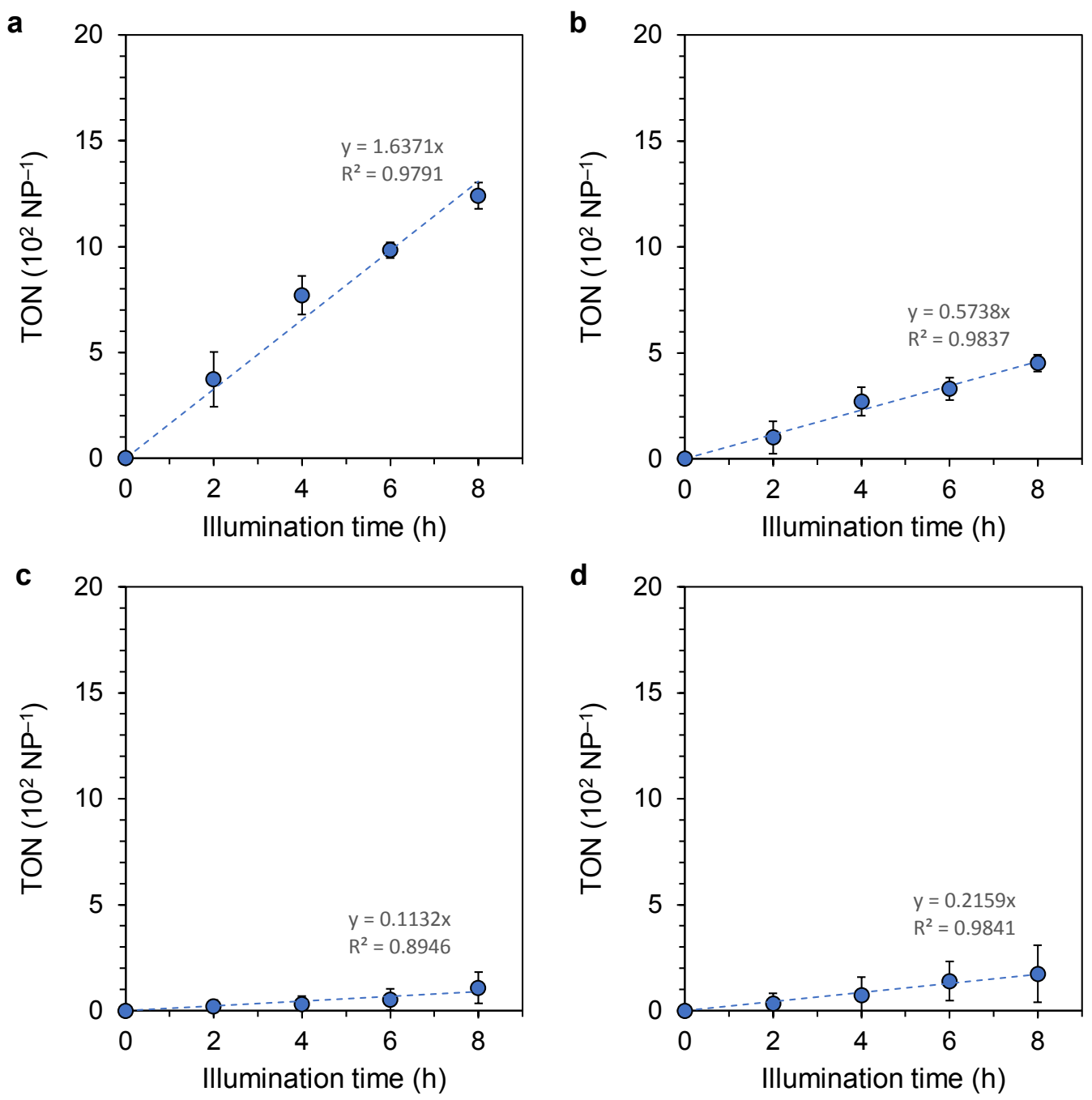

Figure S14. Time course of $\mathrm{H}_{2}$ turnovers in Au-photocatalyzed $\mathrm{CO}_{2}$ reduction in $5 \mathrm{~mol} \%$ EMIM-BF 4 solution of different $\left[\mathrm{H}^{+}\right]$: (a) $1.12 \mathrm{mM}$, (b) $2.95 \mathrm{mM}$, (c) $4.68 \mathrm{mM}$, and (d) 6.92 $\mathrm{mM}$. The photoreactions were conducted under the irradiation of a $\mathrm{CW}$ laser of a wavelength of $532 \mathrm{~nm}$ and an intensity of $1 \mathrm{~W} \mathrm{~cm}^{-2}$. Each data point is the average TON from three identical trials, and the error bar is the standard deviation of these measurements. Each dashed line represents a linear fit to the plot, and the slope yields the average TOF of each product. The TOF values are plotted as a function of the $\left[\mathrm{H}^{+}\right]$in Figure 2a. For appropriate comparison of TOFs, all the plots have the same y-axis scale as the plot in panel (a), which presents conditions at which the highest $\mathrm{H}_{2}$ turnover was observed. 

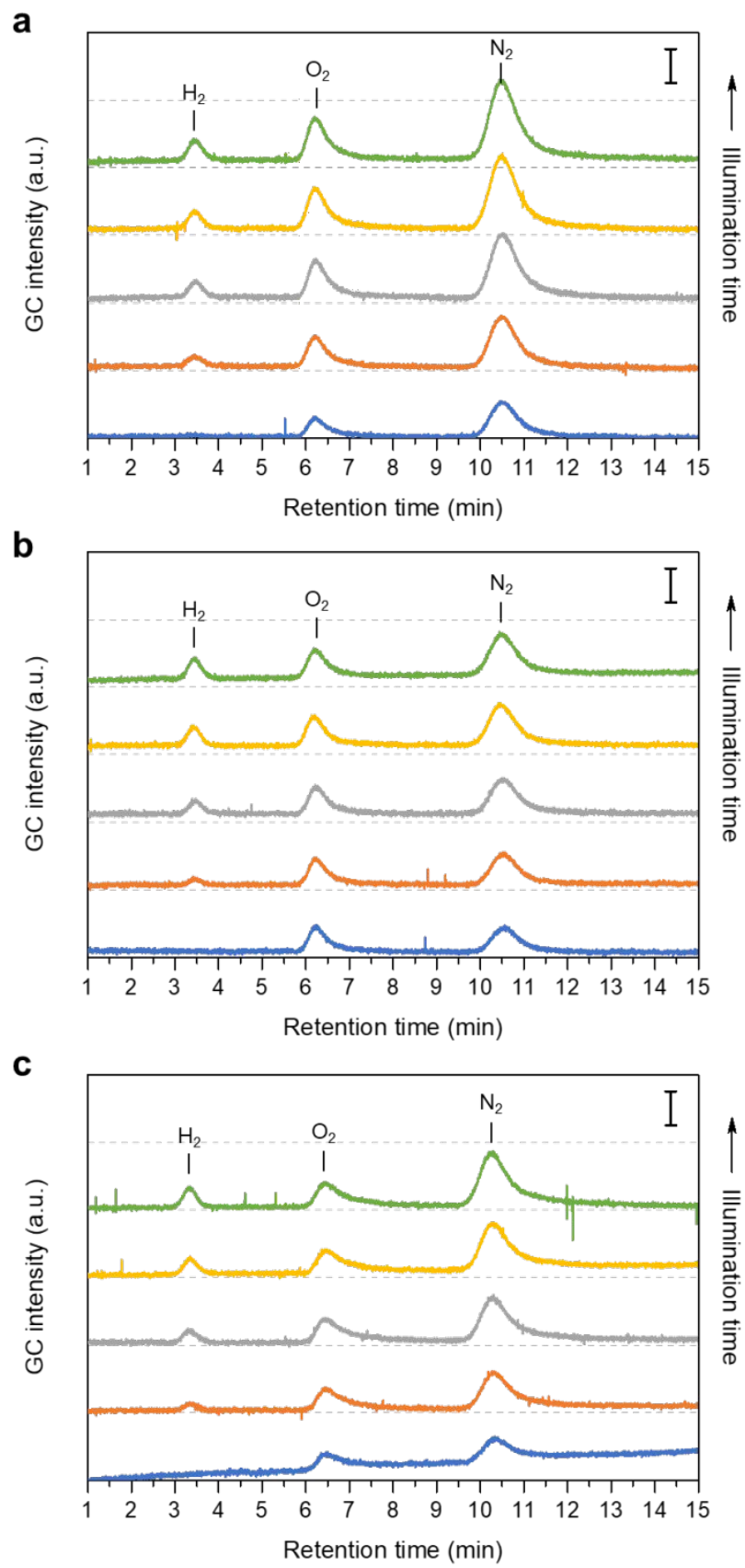

Figure S15. $(\mathrm{a}-\mathrm{c})$ Chromatograms from gas chromatography with a thermal conductivity detector (GC-TCD) obtained at $2 \mathrm{~h}$ intervals in an $8 \mathrm{~h}$ long Au-photocatalyzed $\mathrm{CO}_{2}$ reduction reaction in $5 \mathrm{~mol} \% \mathrm{EMIM}-\mathrm{BF}_{4}$ at $\left[\mathrm{H}^{+}\right]=1.12 \mathrm{mM}$. The photoreaction was conducted under the irradiation of a CW laser of a wavelength of $532 \mathrm{~nm}$ and an intensity of $1 \mathrm{~W} \mathrm{~cm}^{-2}$. Three identical trials were performed, results from which are shown in $(a-c)$. The chromatograms are vertically stacked from the bottom to top in the order of illumination time $(0 \mathrm{~h}, 2 \mathrm{~h}, 4 \mathrm{~h}, 6$ $\mathrm{h}$, and $8 \mathrm{~h}$ ). The chromatograms show an increase in the intensity of GC peak (labeled) associated with $\mathrm{H}_{2}$ with increasing illumination time. The $\mathrm{H}_{2}$ production was quantified from these chromatograms, the time-profile of which is shown in Figure S14a. The $\mathrm{O}_{2}$ and $\mathrm{N}_{2}$ peaks originate from air leftover in the reactor from the reaction mixture preparation, air that possibly leaked into the reactor over the course of the photoreaction, and/or inadvertent air entry during injection of the headspace gas into the GC. Scale bar corresponds to 0.5 a.u.. 

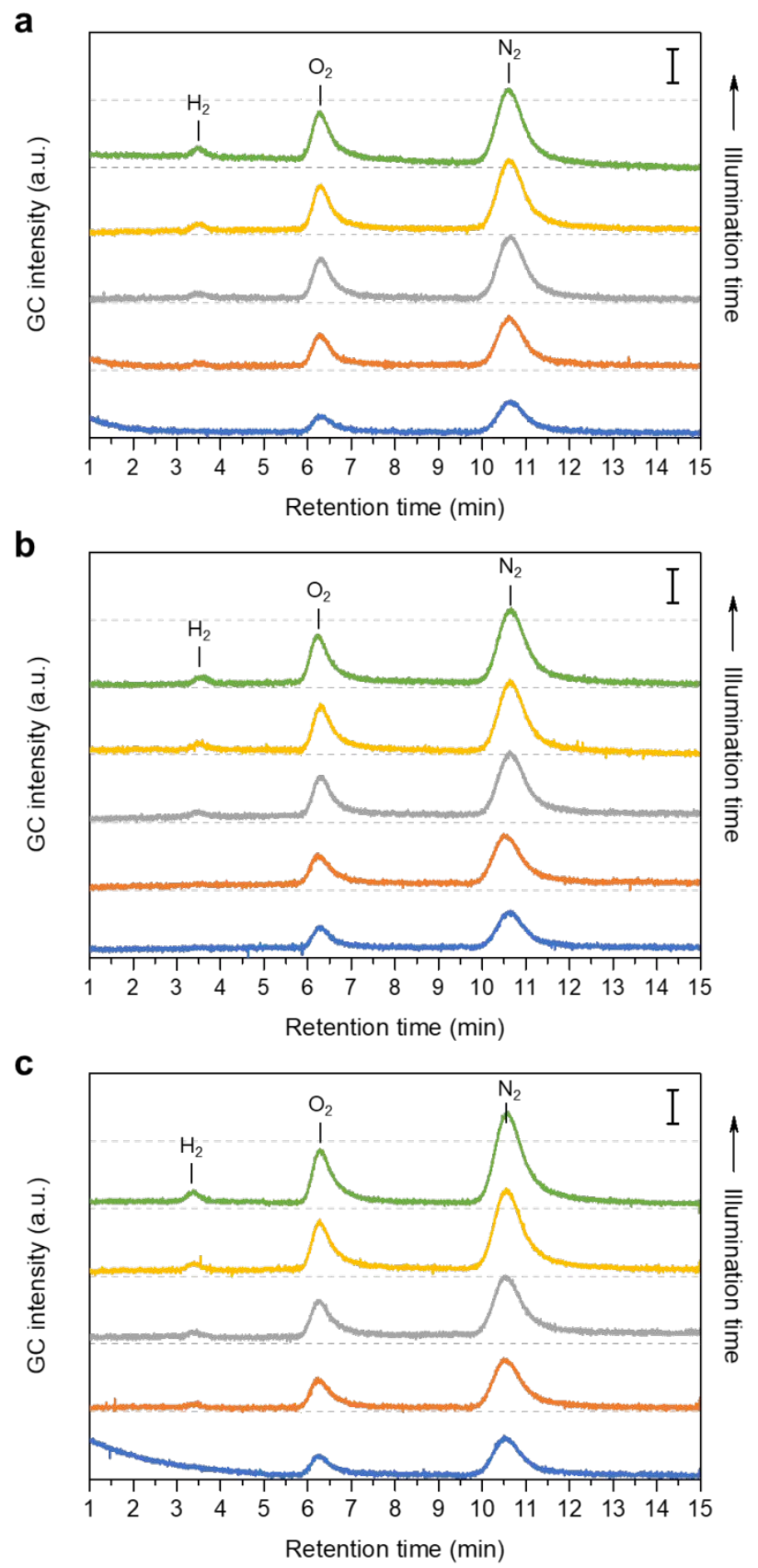

Figure S16. (a-c) GC-TCD chromatograms obtained at $2 \mathrm{~h}$ intervals in an $8 \mathrm{~h}$ long Auphotocatalyzed $\mathrm{CO}_{2}$ reduction reaction in $5 \mathrm{~mol} \% \mathrm{EMIM}_{-} \mathrm{BF}_{4}$ at $\left[\mathrm{H}^{+}\right]=2.95 \mathrm{mM}$. The photoreaction was conducted under the irradiation of a CW laser of a wavelength of $532 \mathrm{~nm}$ and an intensity of $1 \mathrm{~W} \mathrm{~cm}^{-2}$. Three identical trials were performed, results from which are shown in $(\mathrm{a}-\mathrm{c})$. The chromatograms are vertically stacked from the bottom to top in the order of illumination time ( $0 \mathrm{~h}, 2 \mathrm{~h}, 4 \mathrm{~h}, 6 \mathrm{~h}$, and $8 \mathrm{~h})$. The chromatograms show an increase in the intensity of GC peak (labeled) associated with $\mathrm{H}_{2}$ with increasing illumination time. The $\mathrm{H}_{2}$ production was quantified from these chromatograms, the time-profile of which is shown in Figure $\mathrm{S} 14 \mathrm{~b}$. The $\mathrm{O}_{2}$ and $\mathrm{N}_{2}$ peaks originate from air leftover in the reactor from the reaction mixture preparation, air that possibly leaked into the reactor over the course of the photoreaction, and/or inadvertent air entry during injection of the headspace gas into the GC. Scale bar corresponds to 0.5 a.u.. 

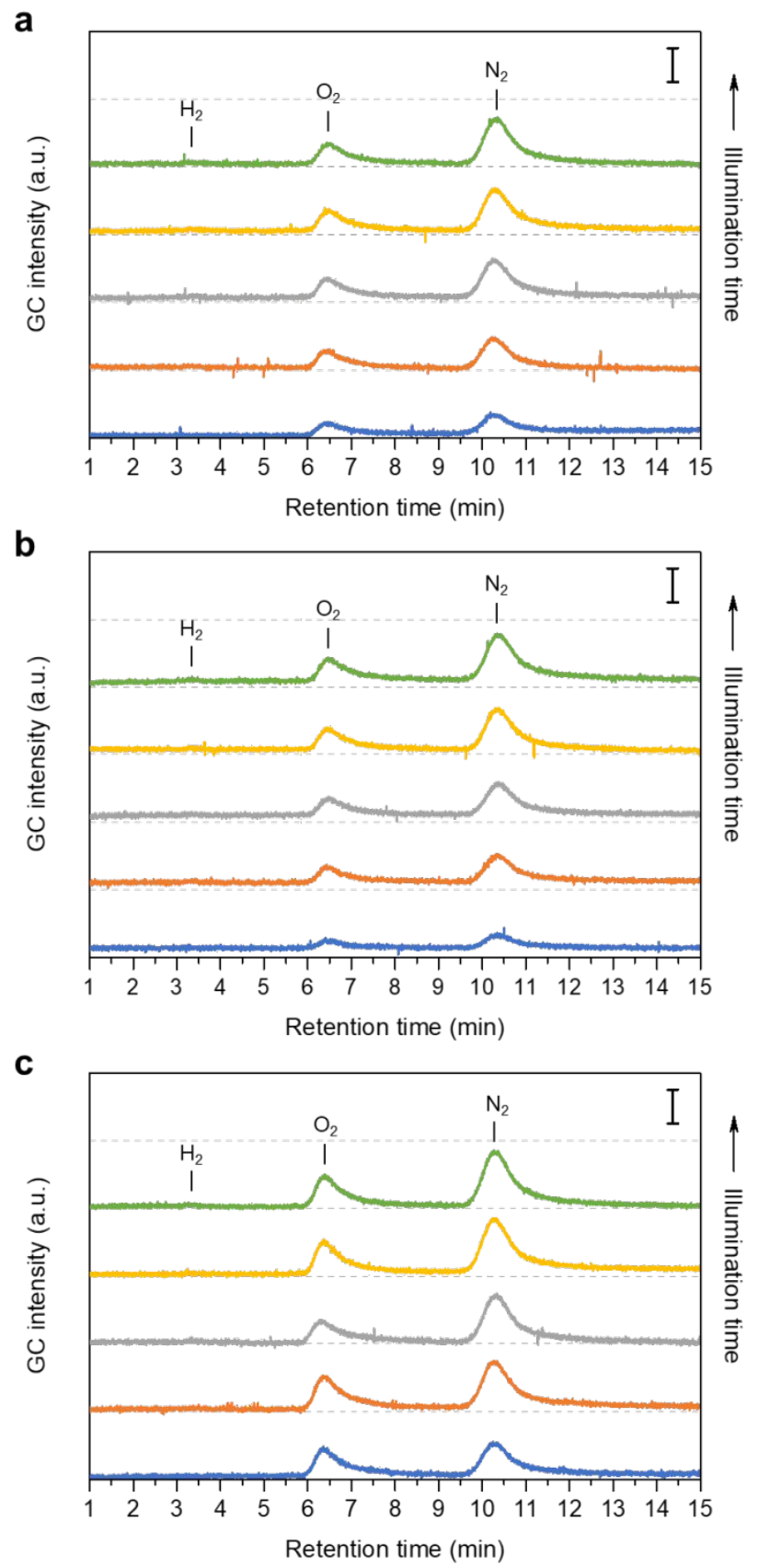

Figure S17. (a-c) GC-TCD chromatograms obtained at $2 \mathrm{~h}$ intervals in an $8 \mathrm{~h}$ long Auphotocatalyzed $\mathrm{CO}_{2}$ reduction reaction in $5 \mathrm{~mol} \% \mathrm{EMIM}^{-\mathrm{BF}_{4}}$ at $\left[\mathrm{H}^{+}\right]=4.68 \mathrm{mM}$. The photoreaction was conducted under the irradiation of a CW laser of a wavelength of $532 \mathrm{~nm}$ and an intensity of $1 \mathrm{~W} \mathrm{~cm}^{-2}$. Three identical trials were performed, results from which are shown in $(\mathrm{a}-\mathrm{c})$. The chromatograms are vertically stacked from the bottom to top in the order of illumination time $(0 \mathrm{~h}, 2 \mathrm{~h}, 4 \mathrm{~h}, 6 \mathrm{~h}$, and $8 \mathrm{~h})$. The chromatograms show little to no increase in the intensity of GC peak (labeled) associated with $\mathrm{H}_{2}$ with increasing illumination time. The $\mathrm{H}_{2}$ production was quantified from these chromatograms, the time-profile of which is shown in Figure S14c. The $\mathrm{O}_{2}$ and $\mathrm{N}_{2}$ peaks originate from air leftover in the reactor from the reaction mixture preparation, air that possibly leaked into the reactor over the course of the photoreaction, and/or inadvertent air entry during injection of the headspace gas into the GC. Scale bar corresponds to 0.5 a.u.. 

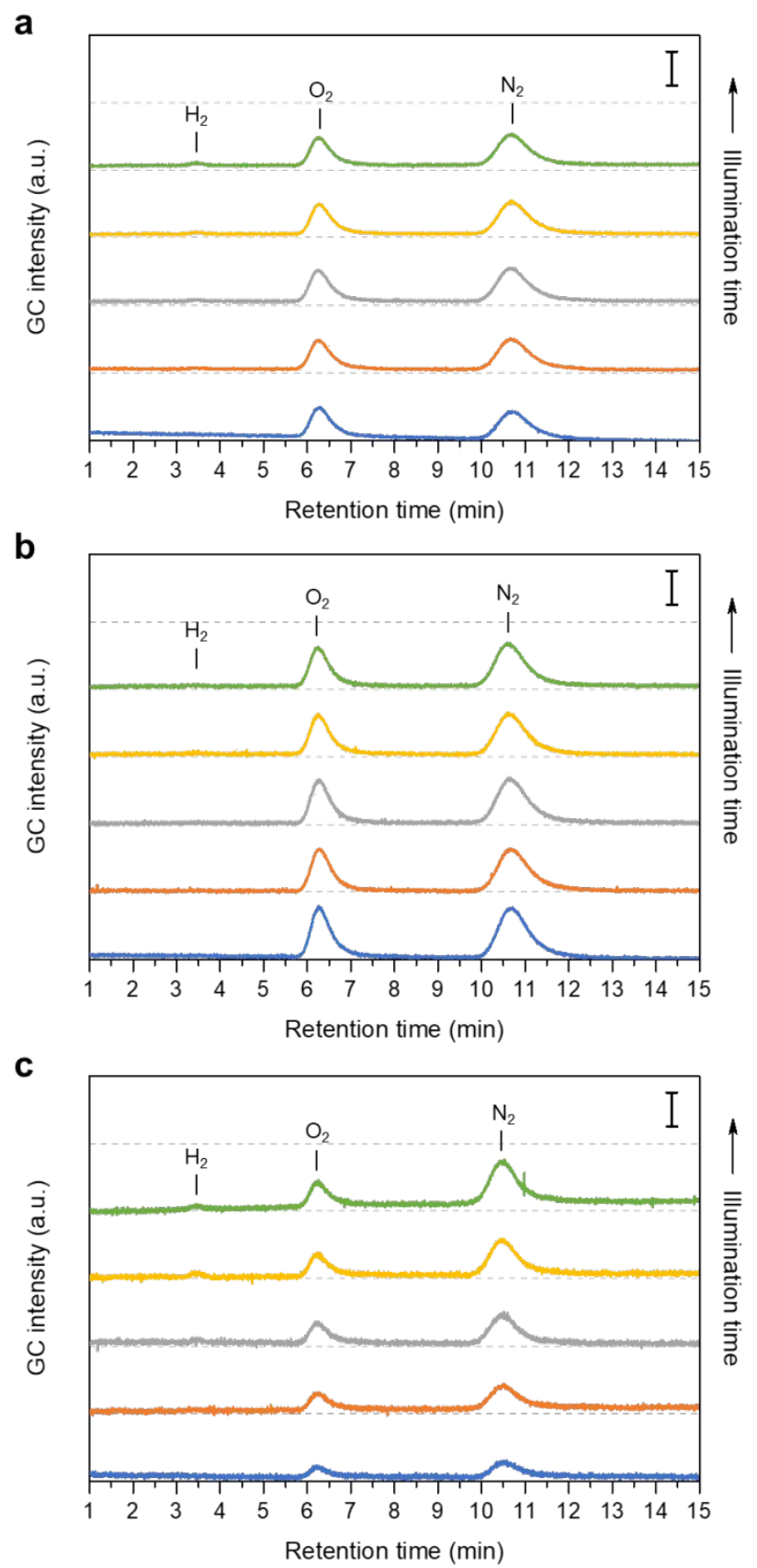

Figure S18. (a-c) GC-TCD chromatograms obtained at $2 \mathrm{~h}$ intervals in an $8 \mathrm{~h}$ long Auphotocatalyzed $\mathrm{CO}_{2}$ reduction reaction in $5 \mathrm{~mol} \% \mathrm{EMIM}^{-\mathrm{BF}_{4}}$ at $\left[\mathrm{H}^{+}\right]=6.92 \mathrm{mM}$. The photoreaction was conducted under the irradiation of a CW laser of a wavelength of $532 \mathrm{~nm}$ and an intensity of $1 \mathrm{~W} \mathrm{~cm}^{-2}$. Three identical trials were performed, results from which are shown in $(\mathrm{a}-\mathrm{c})$. The chromatograms are vertically stacked from the bottom to top in the order of illumination time $(0 \mathrm{~h}, 2 \mathrm{~h}, 4 \mathrm{~h}, 6 \mathrm{~h}$, and $8 \mathrm{~h})$. The chromatograms show a small increase in the intensity of GC peak (labeled) associated with $\mathrm{H}_{2}$ with increasing illumination time. The $\mathrm{H}_{2}$ production was quantified from these chromatograms, the time-profile of which is shown in Figure S14d. The $\mathrm{O}_{2}$ and $\mathrm{N}_{2}$ peaks originate from air leftover in the reactor from the reaction mixture preparation, air that possibly leaked into the reactor over the course of the photoreaction, and/or inadvertent air entry during injection of the headspace gas into the GC. Scale bar corresponds to 0.5 a.u.. 

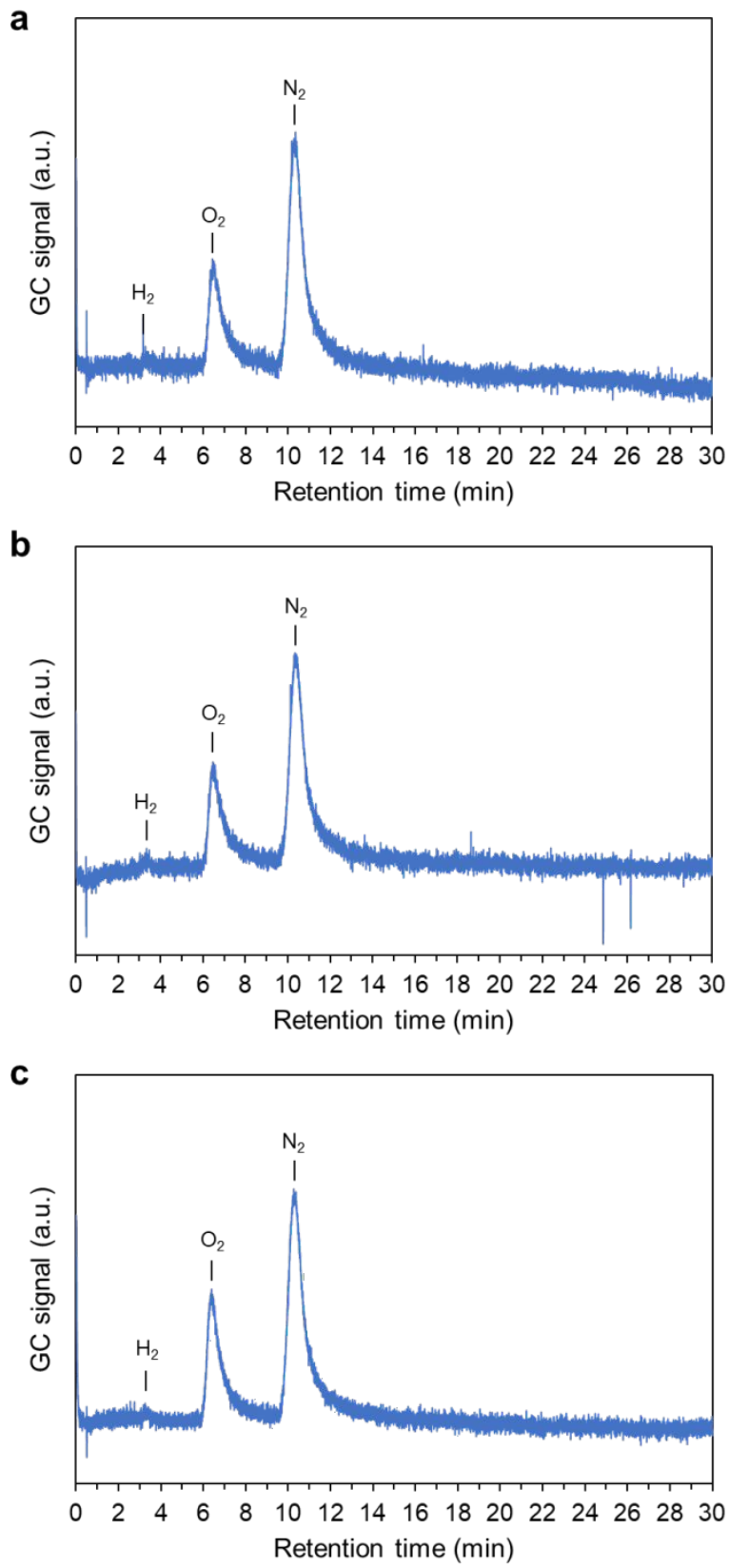

Figure S19. $(\mathrm{a}-\mathrm{c})$ A GC-TCD chromatogram with an extended retention time-range obtained

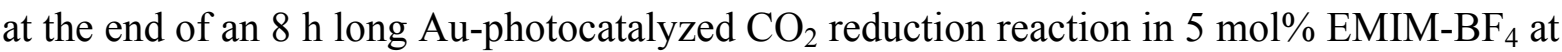
$\left[\mathrm{H}^{+}\right]=4.68 \mathrm{mM}$. The photoreaction was conducted under the irradiation of a CW laser of a wavelength of $532 \mathrm{~nm}$ and an intensity of $1 \mathrm{~W} \mathrm{~cm}^{-2}$. Three identical trials were performed, the chromatograms from which are presented in $(\mathrm{a}-\mathrm{c})$. The extended range chromatograms show $\mathrm{GC}$ peaks (labeled) for $\mathrm{H}_{2}, \mathrm{O}_{2}$, and $\mathrm{N}_{2}$, but no peaks associated with $\mathrm{CO}$ (expected at a retention time of $20.7 \mathrm{~min}$ ) or other gaseous products are observed. The $\mathrm{O}_{2}$ and $\mathrm{N}_{2}$ peaks originate from air leftover in the reactor from the reaction mixture preparation, air that possibly leaked into the reactor over the course of the photoreaction, and/or inadvertent air entry during injection of the headspace gas into the GC. 

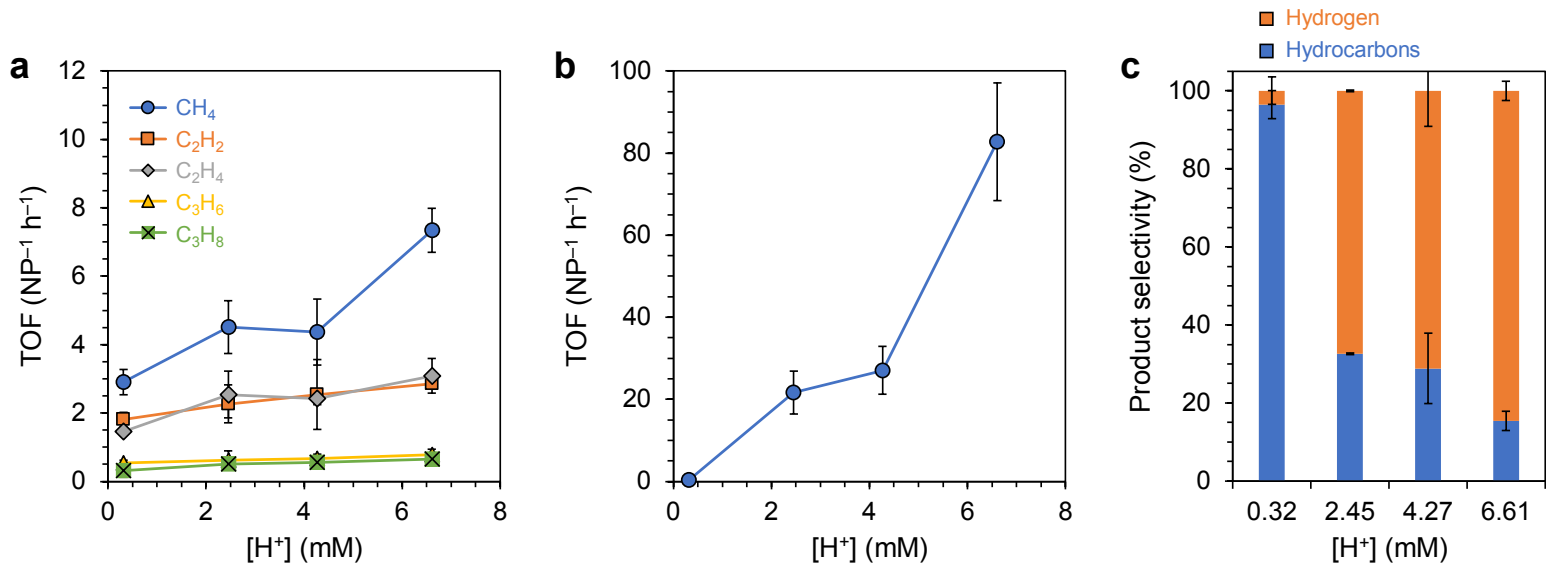

Figure S20. (a) TOFs of hydrocarbon products, (b) TOF of $\mathrm{H}_{2}$, and (c) selectivity toward hydrocarbons (orange bars) and toward $\mathrm{H}_{2}$ (blue bars) as a function of the $\left[\mathrm{H}^{+}\right]$in the photocatalytic reaction conducted in a manner similar to that employed for the results presented in Figure 1a, except for one change: a fraction $(10 \mathrm{vol} \%)$ of the water in the reaction medium was replaced with an equivalent volume of methanol. The selectivity toward hydrocarbons is defined as the (sum of TOFs for all hydrocarbons) $\div$ (sum of TOFs for $\mathrm{H}_{2}$ and all hydrocarbons) $\times 100$. The selectivity toward $\mathrm{H}_{2}$ is defined as the (TOF for $\left.\mathrm{H}_{2}\right) \div$ (sum of TOFs for $\mathrm{H}_{2}$ and all hydrocarbons) $\times 100$. Each data point is the average of results from two identical trials and the error bar represents the standard deviation of these measurements. 


\section{References}

(1) $\mathrm{Yu}, \mathrm{S}$.; Jain, P. K. Plasmonic Photosynthesis of $\mathrm{C}_{1}-\mathrm{C}_{3}$ Hydrocarbons from Carbon Dioxide Assisted by an Ionic Liquid. Nat. Commun. 2019, 10, 2022.

(2) Yu, S; Wilson, A. J.; Heo, J.; Jain, P. K. Plasmonic Control of Multi-Electron Transfer and $\mathrm{C}-\mathrm{C}$ Coupling in Visible-Light-Driven $\mathrm{CO}_{2}$ Reduction on Au Nanoparticles, Nano Lett. 2018, 18, 2189-2194. 